\title{
A eletrodinâmica quântica de Feynman - tradução de sua palestra Nobel
}

\author{
Feynman's quantum electrodynamics - translation of his Nobel lecture \\ Marcel Novaes*10 \\ ${ }^{1}$ Universidade Federal de Uberlandia, Instituto de Física, Uberlândia, MG, Brasil
}

\begin{abstract}
Recebido em 07 de Dezembro, 2017. Revisado em 16 de Fevereiro, 2018. Aceito em 20 de Fevereiro, 2018.
Apresentamos uma tradução para o português da palestra ministrada por Richard P. Feynman por ocasião do recebimento do prêmio Nobel de 1965.

Palavras-chave: Eletrodinâmica quântica, Richard Feynman
\end{abstract}

We present a portuguese translation of Richard P. Feynman's lecture on acceptance of the Nobel prize of 1965.

Keywords: Quantum eletrodynamics, Richard Feynman

\section{Introdução}

Richard P. Feynman recebeu o prêmio Nobel de 1965, compartilhado com Sin-Itiro Tomonaga e Julian Schwinger. De acordo com o comitê, o prêmio lhe foi concedido "por seu trabalho fundamental em eletrodinâmica quântica, com profundas consequências para a física das partículas elementares" 1, 2].

A princípio, ele pensou em não aceitar, por causa da atenção que atrairia da mídia, a pompa envolvida e os infindáveis pedidos para que resumisse seu trabalho "em poucas palavras". Entretanto, acabou aceitando quando foi convencido que uma recusa causaria ainda mais alvoroço.

Por ocasião do recebimento do prêmio, Feynman ministrou uma palestra intitulada The development of the space-time view of quantum electrodynamics. A versão original está disponível em https://www.nobelprize.org/nobel_prizes/ physics/laureates/1965/feynman-lecture.html.

O texto é bastante acessível, narrando a história do envolvimento de Feynman com o assunto em questão 3. e o caminho percorrido por suas ideias ao longo dos anos, fazendo uso de poucas equações. Na próxima seção, apresentamos uma tradução dessa palestra para o português.

*Endereço de correspondência: marcel.novaes@gmail.com

\section{O desenvolvimento da visão espaço-temporal da eletrodinâmica quântica}

Temos o hábito, ao escrever artigos e publicá-los em revistas científicas, de mostrar o trabalho tão acabado quanto possível, de encobrir os caminhos, de não nos preocuparmos com os becos sem saída, de não falar sobre como tivemos uma ideia errada primeiro, e assim por diante. Não há lugar para publicar, de forma digna, o que realmente fizemos para chegar lá, embora haja atualmente algum interesse nesse tipo de coisa. Já que ganhar um prêmio é uma coisa pessoal, pensei que poderia ter licença neste caso para falar de forma pessoal sobre minha relação com a eletrodinâmica quântica, em vez de discutir o assunto de forma refinada e acabada. Ademais, como há três pessoas que ganharam o prêmio de física, se todos falarem sobre eletrodinâmica o tema vai ficar cansativo. O que eu gostaria de contar a vocês hoje é a sequência de eventos, de fato a sequência de ideias, que ocorreu, ao fim da qual eu finalmente emergi com um problema não resolvido, pelo qual acabei ganhando um prêmio.

Eu entendo que um artigo realmente científico seria mais útil, mas artigos desse tipo eu posso publicar em revistas comuns. Portanto, usarei a oportunidade desta Palestra Nobel para fazer algo de menos valor, mas que não posso fazer em outro lugar. Peço ainda sua paciência com outro aspecto. Incluirei nas histórias detalhes que não têm valor científico, nem ajudam na compreensão das ideias. Serão incluídos apenas para tornar a palestra mais interessante.

Trabalhei nesse problema por cerca de oito anos até a publicação final em 1947. O começo de tudo foi no 
Instituto de Tecnologia de Massachusetts, quando eu era aluno de graduação e lia sobre física, aprendendo devagar a respeito das coisas que preocupavam as pessoas, e chegando à conclusão de que o problema fundamental da época era que a teoria quântica da eletricidade e do magnetismo não era completamente satisfatória. Isso eu aprendi em livros como os de Heitler e Dirac. Fui inspirado pelas observações feitas nesses livros; não pelas partes em que tudo era provado, demonstrado cuidadosamente e calculado, porque essas eu não entendia muito bem. Ainda jovem, o que eu podia entender eram os comentários sobre o fato de que aquilo não fazia nenhum sentido - ainda me lembro da última frase do livro do Dirac, "Parece que algumas ideias físicas essencialmente novas são necessárias". Então, encarei isso como um desafio e uma inspiração. Eu também tinha uma desconfiança particular de que, como eles não tinham obtido uma resposta satisfatória para o problema que eu queria resolver, eu não precisava prestar muita atenção ao que haviam feito.

$\mathrm{Eu}$ depreendi dessas leituras que eram duas as dificuldades com as teorias eletrodinâmicas quânticas. A primeira era uma energia infinita de interação do elétron consigo mesmo. Essa dificuldade existia até mesmo na teoria clássica. A outra dificuldade consistia de algumas divergências relacionadas ao número infinito de graus de liberdade do campo. Da forma como eu entendia na época (até onde posso me lembrar) isso advinha simplesmente do fato de que, se quantizamos os osciladores harmônicos do campo (dentro de uma caixa, digamos), cada oscilador tem um estado fundamental de energia $\frac{1}{2} \hbar \omega$ e há um número infinito de modos na caixa, com frequências arbitrariamente altas e, portanto, há uma energia infinita na caixa. Eu hoje percebo que essa não era uma caracterização completamente correta do problema central: ela poderia ser removida simplesmente alterando o zero a partir do qual a energia é medida. De qualquer forma, eu acreditava que a dificuldade estava de alguma forma associada à combinação da interação do elétron consigo mesmo e o número infinito de graus de liberdade do campo.

Bem, parecia-me evidente que a ideia de que uma partícula aja sobre si mesma, de que a força elétrica aja sobre a mesma partícula que a gerou, não é necessária é meio boba, na verdade. Assim, considerei que elétrons não poderiam atuar sobre si mesmos, somente sobre outros elétrons. Isso significa que não existe campo algum. Vejam, se todas as cargas contribuem para criar um campo comum, e se esse campo comum age sobre todas as cargas, então cada carga deve agir sobre si mesma. Ora, era aí que estava o problema, não havia campo. O que ocorre é que, quando você move uma carga, uma outra vai se mover em seguida. Há uma interação direta entre as cargas, ainda que com um atraso. A lei de força que conecta o movimento de uma carga com o de outra inclui um atraso. Chacoalhe esta, aquela chacoalha depois. Um átomo no sol se move; um elétron no meu olho se move oito minutos depois, devida à interação direta entre eles.

Essa visão tem a atraente propriedade de que resolve os dois problemas ao mesmo tempo. Primeiro, posso dizer imediatamente que um elétron não age sobre si mesmo, há apenas interação deste sobre aquele, não há auto-energia! Segundo, não há um número infinito de graus de liberdade no campo, pois não há campo algum. Se insistimos em pensar em termos de coisas como campos, o campo é sempre completamente determinado pela ação das partículas que o produzem. Chacoalhamos esta partícula, ela faz chacoalhar aquela; se queremos pensar em termos de campo, então o campo, se está lá, será inteiramente determinado pela matéria que o gera e, portanto, o campo não tem nenhum grau de liberdade independente e os infinitos devidos aos graus de liberdade seriam assim removidos. De fato, quando olhamos para algum lugar e vemos a luz, sempre podemos "ver" alguma matéria como fonte da luz. Não vemos a luz apenas (com a exceção recente de algumas ondas de rádio que foram encontradas sem fonte material aparente). Meu plano geral era resolver o problema clássico, de modo a me livrar das auto-energias infinitas da teoria clássica, e torcer para que tudo desse certo quando eu fizesse uma teoria quântica.

Esse foi o começo, e a ideia me parecia tão óbvia e elegante que me apaixonei profundamente por ela. E isso, assim como se apaixonar por uma mulher, só é possível se você não souber muito sobre ela, de modo que não veja seus defeitos. Os defeitos vão acabar aparecendo, mas depois que o amor é forte o bastante para prendê-lo a ela. Assim, eu fiquei preso a essa teoria, a despeito das dificuldades, por meu entusiasmo juvenil. Fui fazer pós-graduação e, ao longo desse caminho, aprendi o que havia de errado com a ideia de que em elétron não age sobre si mesmo. Quando aceleramos um elétron, ele irradia energia e precisamos realizar um trabalho extra para compensar essa energia. A força extra em oposição à qual esse trabalho é feito é chamada de força de resistência de radiação. A origem dessa força extra foi identificada, de acordo com Lorentz, como a ação do elétron sobre si mesmo. O primeiro termo dessa ação, do elétron sobre si mesmo, representava uma forma de inércia (não muito satisfatória relativisticamente). Mas esse termo de tipo inercial era infinito para uma carga pontual. $\mathrm{O}$ próximo termo da sequência dava uma taxa de perda de energia, que para uma carga pontual concorda perfeitamente com a taxa obtida calculando quanta energia é irradiada. Assim, a força de resistência de radiação, que é absolutamente necessária para conservação da energia, desaparece se dissermos que a carga não atua sobre si mesma.

Assim, aprendi na época da pós-graduação sobre o defeito óbvio da minha teoria. Mas eu ainda estava apaixonado por ela e ainda pensava que ela tinha a solução para as dificuldades da eletrodinâmica quântica. Portanto, continuei a tentar salvá-la de alguma forma. Devia 
haver alguma ação sobre um elétron acelerado para compensar a resistência de radiação. Mas, se permito apenas que elétrons ajam sobre outros elétrons, a única fonte possível dessa ação é algum outro elétron. Um dia, quando estava trabalhando para o Professor Wheeler e não conseguia resolver o problema que ele me dera, comecei a pensar sobre isso novamente e calculei o seguinte: suponha que há duas cargas - movo a primeira, que vejo como fonte, e isso faz a segunda se mover, mas o movimento da segunda produz um efeito de volta sobre a fonte. Calculei quanto era o efeito sobre a primeira carga, esperando que pudesse dar a força de resistência de radiação. Não deu certo, é claro.

Procurei o Professor Wheeler e contei a ele sobre minhas ideias. Ele disse "sim, mas a resposta que você obtém para o problema com duas cargas que você mencionou vai, infelizmente, depender da carga e da massa da segunda carga e vai variar com o inverso do quadrado da distância $R$ entre as cargas, enquanto a força de resistência de radiação não depende de nada disso". Eu pensei que ele tivesse feito essas contas, mas hoje, tendo me tornado professor, sei que alguém pode ser sábio o suficiente para ver imediatamente o que um aluno de pós-graduação leva semanas para desenvolver. Ele também apontou outra coisa que me incomodou: se tivéssemos uma situação com muitas cargas ao redor da fonte original, com densidade uniforme, e adicionássemos o efeito de todas essas cargas, o inverso de $R^{2}$ seria compensado pelo $R^{2}$ do elemento de volume e teríamos um resultado proporcional à espessura da camada, que poderia ser infinita. Ou seja, teríamos um efeito total infinito agindo sobre a fonte. E finalmente, ele me disse "você esqueceu mais uma coisa, quando a primeira carga é acelerada, a segunda reage depois, e a reação de volta na fonte será ainda mais tarde". Em outras palavras, a ação ocorre no momento errado. Eu imediatamente percebi como sou um cara estúpido, pois o que eu tinha descrito e calculado era apenas reflexão ordinária da luz e não reação de radiação.

Mas, enquanto eu era estúpido, o Professor Wheeler era muito mais esperto. Ele começou a dar uma palestra como se tivesse resolvido tudo antes e estivesse completamente preparado, mas ele não tinha, ele foi resolvendo enquanto falava. Primeiro, ele disse, vamos supor que a reação das cargas no absorvedor [a nuvem eletrônica ao redor da fonte] atinge a fonte por meio de ondas avançadas além das ondas retardadas comuns da luz refletida; de modo que a lei de interação aja para trás no tempo, além de para frente. Eu já era um físico bom o bastante para não dizer "Oh não, não pode ser". Todos os físicos hoje sabem, tendo estudado Einstein e Bohr, que às vezes uma ideia que parece completamente paradoxal a princípio, se analisada até o fim em todos os detalhes e situações experimentais, pode, de fato, não ser paradoxal. Não me incomodou que o Professor Wheeler usasse ondas avançadas para a reação - uma solução das equações de Maxwell, que anteriormente não tinha sido usada.
O Professor Wheeler usou ondas avançadas para obter a reação no momento certo e então sugeriu isto: se houvesse muitos elétrons no absorvedor, haveria um índice de refração $n$ e as ondas retardadas vindas da fonte teriam seus comprimentos de onda levemente modificados ao passar pelo absorvedor. Se imaginarmos que as ondas avançadas chegam sem experimentar esse índice - por quê? Não sei, vamos imaginar isso - então haverá uma mudança gradual na fase entre o sinal original e o retorno, de modo que as contribuições funcionam como se viessem de uma espessura finita, aquela da primeira zona da onda (mais especificamente, até a profundidade em que a fase do meio é apreciavelmente diferente do que seria no vácuo, uma profundidade proporcional a $\lambda /(n-1))$. Quanto menos elétrons houver, menor a contribuição, mas mais grossa será a camada que efetivamente contribui, porque com menos elétrons o índice difere pouco de 1. Quanto maior a carga dos elétrons, mais eles contribuem, mas mais fina é a camada efetiva, porque o índice seria maior. Quanto fizemos a estimativa (calculada sem muito cuidado com os fatores numéricos) resultou, como esperado, que a ação sobre a fonte era completamente independente das propriedades das cargas no absorvedor. Ademais, era do jeito certo para representar a resistência de radiação, mas não conseguíamos saber se tinha exatamente a magnitude certa. Ele me mandou para casa com ordens de descobrir quanto exatamente de ondas avançadas e quanto de retardadas precisávamos para obter o resultado certo, e depois entender o que aconteceria com os efeitos avançados que seriam esperados se colocássemos uma carga de teste próxima da fonte. Afinal, se todas as cargas geram efeitos avançados, além de retardados, não deveria a carga de teste ser afetada pelas ondas avançadas da fonte?

Encontrei que a resposta certa aparece se as ondas forem metade avançadas e metade retardadas. Ou seja, deve-se usar a solução da equação de Maxwell que é simétrica no tempo e a razão pela qual não vemos efeitos avançados em um ponto próximo da fonte, a despeito do fato de a fonte estar produzindo um campo avançado é este: suponha que a fonte está rodeada por uma caixa esférica absorvedora a dez segundos luz de distância, e que a carga de teste está um segundo à direita da fonte. Então, a carga de teste está a onze segundos de algumas partes da caixa e nove segundos de outras partes. A fonte agindo no tempo $t=0$ induz movimento na caixa no tempo $t=+10$. Efeitos avançados podem atingir a carga de teste até onze segundos antes, ou $t=-1$. Esse é o momento em que as ondas avançadas diretas da fonte devem alcançar a carga de teste, e acontece que os dois efeitos são exatamente iguais e opostos e se cancelam! No instante posterior $t=+1$, efeitos sobre a carga de teste vindos da fonte e da caixa são novamente iguais, mas agora são do mesmo sinal e se somam para converter a meia onda retardada da fonte em uma onda inteira.

Assim, ficou claro que havia uma possibilidade de que, se imaginássemos que todas as ações se davam através 
de soluções metade avançadas e metade retardadas das equações de Maxwell e que todas as fontes estão rodeadas por material que absorve a luz que é emitida, então poderíamos entender a resistência de radiação como ação direta das cargas do absorvedor por meio de ondas avançadas sobre a fonte. Muitos meses foram dedicados a checar todos esses pontos. Eu trabalhei para mostrar que tudo era independente da forma da caixa, e assim por diante, e que os efeitos avançados realmente se cancelavam em todos os casos. Sempre tentávamos aumentar a eficiências das nossas demonstrações e ver com mais e mais clareza por quê elas funcionavam. Não vou entediálos com os detalhes disso tudo. Por termos usado ondas avançadas, tínhamos muitos paradoxos aparentes, que gradualmente reduzimos um por um e vimos que não havia mesmo nenhuma dificuldade lógica com a teoria. Era perfeitamente satisfatória. Também descobrimos que poderíamos reformular a coisa de outro modo, usando um princípio de mínima ação. Uma vez que meu plano original era descrever tudo diretamente em termos de movimentos de partículas, eu desejava representar a nova teoria sem dizer nada sobre campos. Conseguimos uma ação envolvendo apenas os movimentos das cargas, cuja variação fornecia as equações de movimento das cargas. A expressão para essa ação A é

$$
\begin{aligned}
& A=\sum_{i} m_{i} \int\left(\dot{X}_{\mu}^{i} \dot{X}_{\mu}^{i}\right)^{\frac{1}{2}} d \alpha_{i} \\
& +\frac{1}{2} \sum_{\substack{i j \\
i \neq j}} e_{i} e_{j} \iint \delta\left(I_{i j}^{2}\right) \dot{X}_{\mu}^{i}\left(\alpha_{i}\right) \dot{X}_{\mu}^{j}\left(\alpha_{j}\right) d \alpha_{d} \alpha_{j}(1)
\end{aligned}
$$

onde

$$
I_{i j}^{2}=\left[X_{\mu}^{i}\left(\alpha_{i}\right)-X_{\mu}^{j}\left(\alpha_{j}\right)\right]\left[X_{\mu}^{i}\left(\alpha_{i}\right)-X_{\mu}^{j}\left(\alpha_{j}\right)\right]
$$

e onde $X_{\mu}^{i}\left(\alpha_{i}\right)$ é o quadrivetor posição da $i$-ésima partícula como função de algum parâmetro $\alpha_{i}$, e $\dot{X}_{\mu}^{i}\left(\alpha_{i}\right)$ é $d X_{\mu}^{i}\left(\alpha_{i}\right) / d \alpha_{i}$. O primeiro termo é a integral do tempo próprio, a ação comum da mecânica relativística de partículas livres de massa $m_{i}$ (usamos a tradicional soma sobre o índice repetido $\mu$ ). O segundo termo representa a interação elétrica entre as cargas. Está somado sobre cada par de cargas (o fator $\frac{1}{2}$ é para contar cada par uma única vez, o termo $i=j$ é omitido para evitar auto-interação). A interação é uma integral dupla sobre uma função $\delta$ do quadrado do intervalo espaço-temporal $I^{2}$ entre dois pontos nos caminhos. Assim, a interação ocorre somente quando esse intervalo é nulo, ou seja, sobre cones de luz. O fato de que a interação é exatamente metade avançada e metade retardada permitiu que pudéssemos escrever um tal princípio de mínima ação, enquanto que interação por meio de ondas exclusivamente retardadas não pode ser escrita dessa forma.

Assim, toda a eletrodinâmica clássica está contida nessa forma simples. Parecia bom e, portanto, era sem dúvida verdade, ao menos para um principiante. Fornece automaticamente efeitos metade avançados e metade retardados e não contém campos. Omitindo da soma o termo $i=j$ eu omito a auto-interação e não tenho mais uma auto-energia infinita. Essa era a solução tão esperada para o problema de uma eletrodinâmica clássica livre de infinitos.

É claro que podemos recuperar os campos, se quisermos, mas temos que prestar atenção ao campo produzido por cada partícula separadamente, porque para encontrar o campo correto que age sobre cada partícula precisamos excluir o campo que ela própria cria. Um único campo universal para o qual todas contribuem não funciona. Essa ideia havia sido sugerida anteriormente por Frenkel e por isso nós os chamamos de campos de Frenkel. Essa teoria, que permitia apenas partículas agindo sobre as outras, era equivalente a campos de Frenkel usando soluções metade avançadas e metade retardadas.

Houve várias sugestões de modificações interessantes para a eletrodinâmica. Discutimos várias delas, mas vou contar sobre apenas uma. Era trocar a função $\delta$ por uma outra função, digamos $f\left(I_{i j}^{2}\right)$, que não fosse infinitamente localizada. Em vez de ter uma ação que ocorre somente quando o intervalo entre as cargas é exatamente zero, substituiríamos a função $\delta\left(I^{2}\right)$ por algo com um pico estreito. Digamos que $f(Z)$ é grande somente em torno de $Z=0$ e que tem uma largura de ordem $a^{2}$. Interações ocorrerão quando $T^{2}-R^{2}$ for aproximadamente de ordem $a^{2}$, onde $T$ é a diferença temporal e $R$ a separação espacial entre as cargas. Pode parecer que isso difere da experiência, mas se $a$ é uma distância pequena, tipo $10^{-13} \mathrm{~cm}$, então temos que o retardo temporal $T$ na ação é aproximadamente $\sqrt{R^{2} \pm a^{2}}$, ou aproximadamente, se $R$ for muito maior que $a, T=R \pm a^{2} / 2 R$. Isso significa que o desvio entre o tempo $T$ e o tempo teórico $R$ de Maxwell fica menor quanto mais longe as cargas estiverem. Portanto, todas as teorias envolvidas na análise de geradores, motores, etc., de fato, todos os testes da eletrodinâmica feitos desde o tempo de Maxwell estariam adequadamente satisfeitos se $a$ fosse $10^{-13} \mathrm{~cm}$. Se $R$ é da ordem de um centímetro, o desvio em $T$ é de apenas $10^{-26}$ segundos. Assim, era possível alterar a teoria de maneira simples e ainda concordar com todas as observações da eletrodinâmica clássica. Não tínhamos ideia de qual função $f$ usar, mas era uma possibilidade interessante para ter em mente quando fôssemos desenvolver a eletrodinâmica quântica.

Também nos ocorreu que se fizéssemos isso (trocar $\delta$ por $f$ ) poderíamos restaurar o termo $i=j$ na soma, porque ele agora representaria, de forma relativisticamente invariante, uma ação finita da carga sobre si mesma. De fato, era possível mostrar que, se fizéssemos isso, o principal efeito da auto-interação (para acelerações não muito altas) era produzir uma modificação na massa. Aliás, não havia necessidade de um termo de massa $m_{i}$; toda a massa mecânica poderia ser auto-interação eletromagnética. Poderíamos, se quiséssemos, ter uma outra teoria com uma expressão ainda mais simples para a ação $A$, na qual apenas o segundo termo da equação (1) é mantido, 
mas com a soma incluindo todos os $i$ e $j$ e uma função $f$ em lugar de $\delta$. Tal forma simples representaria toda a eletrodinâmica clássica, o que, aparte a gravitação, é essencialmente toda a física clássica.

Ainda que possa parecer confuso, estou descrevendo várias teorias alternativas diferentes ao mesmo tempo. $\mathrm{O}$ importante a ser notado neste momento é que tínhamos todas em mente como possibilidades diferentes. Havia várias soluções possíveis para as dificuldades da eletrodinâmica clássica e qualquer delas poderia servir como bom ponto de partida para a solução das dificuldades da eletrodinâmica quântica.

Gostaria de enfatizar que eu já estava ficando acostumado a um ponto de vista diferente do comum. Na visão tradicional, as coisas são discutidas como funções do tempo. Por exemplo, se temos o campo neste instante, uma equação diferencial nos dará o campo no próximo instante e assim por diante; um método, que chamarei de método Hamiltoniano, o método temporal. Nós tínhamos, em contraste (na equação (1), por exemplo) algo que descreve o caráter do caminho através de todo o espaço-tempo. O comportamento da natureza é determinado dizendo que todo o seu espaço-tempo tem um certo caráter. Para uma ação como (1), as equações obtidas por variação de $X_{\mu}^{i}\left(\alpha_{i}\right)$ não são nada simples de colocar numa forma Hamiltoniana. Se queremos utilizar como variáveis apenas as coordenadas das partículas, então podemos falar sobre as propriedades dos caminhos - mas o caminho de uma partícula em dado instante é afetado pelo caminho de outra em um instante diferente. Se tentarmos descrever, portanto, as coisas de um modo diferencial, falando sobre as condições presentes das partículas e sobre como essas condições presentes vão afetar o futuro, isso não será possível apenas com partículas, porque algo que a partícula fez no passado vai afetar o futuro.

Portanto, precisamos de muitas variáveis auxiliares para ter em conta tudo que a partícula fez no passado. Essas são as chamadas variáveis de campo. Também teremos de dizer qual é o campo no presente momento, se queremos ser capazes de saber o que vai acontecer depois. Do ponto de vista espaço-temporal do princípio de mínima ação, o campo desaparece na forma de meras variáveis auxiliares requeridas pelo método Hamiltoniano.

Como subproduto desse ponto de vista, recebi um dia um telefonema do Professor Wheeler no departamento de pós-graduação de Princeton, no qual ele disse "Feynman, eu sei por que todos os elétrons têm a mesma carga e a mesma massa". "Por quê?" "Porque são todos o mesmo elétron!". Ele explicou no telefone: "imagine que as linhas de mundo que estávamos considerando no espaçotempo, em vez de ir apenas para frente no tempo fossem um tremendo emaranhado e que, quando cortamos esse emaranhado por um plano de tempo fixo, vemos muitas linhas do tempo que representam muitos elétrons, exceto por uma coisa. Se em um corte temos uma linha de elétron ordinário, em outro corte no qual ela está revertida e vem do futuro temos o sinal errado no tempo próprio na quadrivelocidade - e isso seria equivalente a mudar o sinal da carga e, portanto, essa parte da linha agiria como um pósitron". "Mas, professor", eu disse, "não há tantos pósitrons quanto elétrons". "Ora, talvez estejam escondidos dentro dos prótons ou algo do tipo", ele disse. Eu não levei a ideia dele de que todos os elétrons são o mesmo tão a sério quando levei a observação de que pósitrons podem ser representados simplesmente como elétrons vindos do futuro para o passado em uma seção de suas linhas de mundo. Essa parte eu roubei!

Resumindo, quando terminei tudo isso, como físico eu havia ganho duas coisas. Primeiro, eu sabia muitas maneiras diferentes de formular a eletrodinâmica clássica, com diferentes abordagens matemáticas. Fiquei sabendo como expressar o tema de todas as formas. Segundo, eu tinha outro ponto de vista - baseado no espaço-tempo e alguma falta de respeito pelo método Hamiltoniano de descrever a física.

Gostaria de me interromper aqui para fazer um comentário. O fato de que a eletrodinâmica pode ser formulada de tantas maneiras - as equações diferenciais de Maxwell, os princípios de mínimo com campos, princípios de mínimo sem campos, todas as maneiras diferentes, era algo que eu sabia, mas nunca entendi. Sempre me pareceu estranho que as leis fundamentais da física, depois de descobertas, podem ser formuladas de tantas maneiras diferentes que não são obviamente idênticas mas que, com um pouco de manipulação matemática, é possível demonstrar sua relação. Um exemplo é a equação de Schrödinger e a formulação de Heisenberg da mecânica quântica. Eu não sei por que isso é assim - permanece um mistério, mas é algo que aprendi com a experiência. Há sempre uma outra maneira de dizer a mesma coisa e que não se parece em nada com a maneira que usamos antes. Não sei qual a razão disso. Acho que é uma representação da simplicidade da natureza. Uma coisa como a lei do inverso do quadrado é perfeita para ser representada como uma solução da equação de Poisson, o que é, portanto, uma maneira bem diferente de dizer a mesma coisa e que não se parece em nada com a maneira que usamos antes. Não sei o que isso significa, por que a natureza escolhe essas formas curiosas, mas talvez seja uma maneira de definir simplicidade. Talvez uma coisa seja simples se você pode descrevê-la de várias maneiras diferentes sem perceber imediatamente que está descrevendo a mesma coisa.

Eu estava convencido de que, como tínhamos resolvido o problema da eletrodinâmica clássica (e completamente de acordo com meu programa do M.I.T., utilizando apenas interação direta entre partículas, de modo a tornar campos desnecessários), tudo ia definitivamente dar certo. Eu estava convencido de que tudo o que tinha a fazer era criar uma teoria quântica análoga à clássica e tudo estaria resolvido. Então, o problema é criar uma teoria quântica que tenha como análogo clássico a expressão (1). Só que não há uma maneira única de criar uma 
teoria quântica a partir da mecânica clássica, apesar de todos os livros-texto acharem que há. O que eles dizem é para achar as variáveis de momento e trocá-las por $(\hbar / i)(\partial / \partial x)$, mas eu não podia encontrar uma variável de momento, porque não havia nenhuma.

O estilo da mecânica quântica da época era escrever as coisas no famoso formalismo Hamiltoniano - na forma de uma equação diferencial, que descreve como a função de onda muda de instante a instante, e em termos de um operador, H. Se a física clássica pudesse ser reduzida a uma forma Hamiltoniana, estava tudo certo. Mas o princípio de mínima ação não garante um formalismo Hamiltoniano se a ação depender de algo mais que apenas as posições e as velocidades todas no mesmo instante de tempo. Se a ação for a integral de uma função (normalmente chamada de Lagrangiana) das posições e velocidades todas no mesmo instante de tempo

$$
S=\int L(\dot{x}, x) d t
$$

então você pode começar com a Lagrangiana e passar para a Hamiltoniana e criar a versão quântica, mais ou menos diretamente. Mas essa coisa (1) depende das variáveis, das posições em tempos diferentes e, portanto, não é óbvio como devemos construir o análogo quântico.

Eu tentei - eu me esforçava de várias maneiras. Uma delas era a seguinte: se eu tivesse osciladores harmônicos interagindo com um atraso temporal, eu poderia encontrar os modos normais e tentar adivinhar que a teoria quântica dos modos normais era a mesma que para osciladores simples e então meio que reconstruir o caminho de volta para as variáveis originais. Tive sucesso em fazer isso e esperava generalizar para outros osciladores harmônicos, mas infelizmente aprendi algo que muita gente já aprendeu: o oscilador harmônico é simples demais. Muitas vezes podemos entender como ele funciona na teoria quântica mas não saber muito sobre como generalizar os resultados para outros sistemas. De modo que isso não me ajudou muito. Mas, enquanto eu estava lutando com esse problema, fui até uma festa na Taverna Nassau em Princeton. Havia um sujeito, recém-chegado da Europa (Herbert Jehle), que veio e se sentou ao meu lado. Europeus são muito mais sérios que nós americanos e acham que uma festa é um bom lugar para discutir assuntos intelectuais. Ele se sentou ao meu lado e disse, "o que você está fazendo" e eu disse "estou bebendo cerveja". Então percebi que ele queria saber que trabalho eu estava fazendo e eu contei que estava lutando com esse problema e simplesmente virei para ele e disse: "ouça, você sabe alguma maneira de estudar mecânica quântica, começando com uma ação - uma maneira na qual a ação entre na mecânica quântica?". "Não", ele disse, "mas Dirac tem um artigo no qual a Lagrangiana, pelo menos, entra na mecânica quântica. Vou te mostrar amanhã".

No dia seguinte, nós fomos à Biblioteca de Princeton - eles têm umas salinhas laterais para discussões - e ele me mostrou esse artigo. O que o Dirac fazia era o seguinte: Há na mecânica quântica uma quantidade muito importante que conduz a função de onda de um instante a outro, além da equação diferencial mas equivalente a ela, um tipo de núcleo, que podemos chamar de $K\left(x, x^{\prime}\right)$, que transforma a função de onda $\psi(x)$, conhecida no tempo $t$, na função de onda $\psi\left(x^{\prime}\right)$, no tempo $t+\epsilon$. Dirac observava que essa função $K$ era análoga à quantidade em mecânica clássica que você obteria se calculasse a exponencial de $i \epsilon$ multiplicado pela Lagrangiana $L(\dot{x}, x)$, imaginando que essas duas posições $x, x^{\prime}$ correspondem aos tempos $t$ e $t+\epsilon$. Em outras palavras,

$$
K\left(x^{\prime}, x\right) \quad \text { é análogo a } e^{i \epsilon L\left(\frac{x^{\prime}-x}{\epsilon}, x\right) / \hbar}
$$

O Professor Jehle me mostrou isso, eu li e perguntei "o que ele quer dizer com 'análogo'? De que serve isso?" e ele disse "vocês, americanos! Sempre querem achar um uso para tudo!". Eu disse que achava que Dirac queria dizer que eram iguais. "Não", ele disse, "não quer dizer que são iguais". "Bem", disse eu, "vamos ver o que acontece se os tomarmos iguais".

Então eu simplesmente postulei que eram iguais, usando o exemplo simples no qual a Lagrangiana é dada por $\frac{1}{2} M \dot{x}^{2}-V(x)$, mas logo descobri que era preciso colocar uma constante de proporcionalidade $A$, adequadamente ajustada. Quando substituí $A e^{i \epsilon L / \hbar}$ por $K$ eu obtive

$$
\psi\left(x^{\prime}, t+\epsilon\right)=\int A \exp \left[\frac{i \epsilon}{\hbar} L\left(\frac{x^{\prime}-x}{\epsilon}, x\right)\right] \psi(x, t) d x
$$

e então expandi tudo em série de Taylor e encontrei e equação de Schrödinger. Então me voltei para o Professor Jehle, sem entender muito bem, e disse "está vendo, o Professor Dirac quis dizer que eram proporcionais". Os olhos do Professor Jehle estavam esbugalhados - ele tinha tirado um bloco de papel e estava copiando tudo da lousa rapidamente e disse "não, não, isto é uma descoberta importante. Vocês americanos estão sempre se perguntando como é que as coisas podem ser usadas. É uma ótima maneira de fazer descobertas!". Achei que estivesse entendendo o que Dirac tinha querido dizer, mas estava na verdade descobrindo que o que Dirac pensara que era análogo era, de fato, igual. Eu finalmente tinha, assim, a conexão entre a Lagrangiana e a mecânica quântica, mas ainda com funções de onda e tempos infinitesimais.

Deve ter sido um ou dois dias depois, quando eu estava deitado na cama pensando sobre essas coisas, que imaginei o que aconteceria se calculasse a função de onda depois de um intervalo de tempo finito.

Eu colocaria um desses fatores $e^{i \epsilon L}$ e isso me daria a função no momento seguinte, $t+\epsilon$, e então eu poderia substituir de volta e obter outro fator $e^{i \epsilon L}$, que daria a função no momento seguinte, $t+2 \epsilon$, e assim por diante. Dessa forma, me peguei pensando em um grande número de integrais, uma depois da outra, em sequência. Se o integrando era o produto das exponenciais, então é claro que era a exponencial da soma de termos do tipo $\epsilon L$. Mas $L$ é a Lagrangiana e $\epsilon$ é como um intervalo de 
tempo $d t$, de modo que uma soma de termos como esses é exatamente como uma integral. É como a fórmula de Riemann para a integral $\int L d t$; tomamos o valor em cada ponto e somamos tudo. Temos que tomar o limite $\epsilon \rightarrow 0$, é claro. Assim, a conexão entre a função de onda em um instante e a função de onda em outro instante por de ser obtida através de um número infinito de integrais (porque $\epsilon$ vai a zero, é claro) da exponencial de $(i S / \hbar)$, onde $S$ é a ação (3). Finalmente, tive sucesso em representar a mecânica quântica diretamente em termos da ação $S$.

Isso levou mais tarde à ideia de amplitude de um caminho; para cada maneira que uma partícula tem de ir de um ponto a outro do espaço-tempo, existe uma amplitude. Essa amplitude é a exponencial de $(i / \hbar)$ vezes a ação do caminho. As amplitudes dos vários caminhos se somam. Essa é, portanto, uma terceira maneira de descrever a mecânica quântica, que parece ser bem diferente das de Schrödinger e Heisenberg, mas que é equivalente a elas.

Logo depois de fazer alguns testes com essa coisa, o que eu queria fazer era substituir a ação (1) no lugar da (3). O primeiro problema é que eu não conseguia fazer o negócio funcionar no caso relativístico de spin meio. Entretanto, apesar de conseguir lidar apenas com o caso não-relativístico, eu podia tratar a luz ou a interações com fótons perfeitamente bem simplesmente adicionando os termos de interação de (1) em qualquer ação, trocando os termos de massa pelo termo não-relativístico $\left(M \dot{x}^{2} / 2\right) d t$. Quando a ação tem um atraso, como era o caso agora, e envolvia mais de um instante, eu tinha que esquecer a ideia de função de onda. Ou seja, não podia mais descrever o programa assim: dada a amplitude para todas as posições num certo instante, calcule as amplitudes em outro instante. Entretanto, isso não causou muito problema. Só significava que precisava desenvolver uma nova ideia. Em vez de funções de onda podemos falar da seguinte maneira: se uma fonte de certo tipo emite uma partícula e um detector a recebe, podemos dizer a amplitude de que a fonte emita e o receptor receba. Fazemos isso sem especificar o instante exato em que a fonte emite ou o instante exato em que o receptor recebe, sem tentar especificar o estado de qualquer coisa em instantes de tempo intermediários, mas tão somente encontrando a amplitude para o experimento completo. E assim poderíamos discutir como aquela amplitude mudaria se houvesse um espalhamento no meio, ou se rodássemos e alterássemos ângulos, e assim por diante, sem realmente ter nenhuma função de onda.

Foi possível descobrir o que os antigos conceitos de energia e momento significavam com essa ação generalizada. Eu acreditava possuir uma teoria quântica da eletrodinâmica clássica, ou na verdade dessa nova eletrodinâmica clássica descrita pela ação (1). Fiz alguns testes. Se eu tomasse o ponto de vista do campo de Frenkel, que era mais diferencial, poderia convertê-lo diretamente para a mecânica quântica de modo mais convencional. O único problema seria como especificar em mecânica quântica a condição de contorno de usar apenas soluções metade avançadas e metade retardadas. Com alguma criatividade na hora de definir o que isso queria dizer, encontrei que a mecânica quântica com campos de Frenkel, mais a condição de contorno especial, me dava de volta a ação (1) na forma de uma mecânica quântica com retardo. Assim, várias coisas indicavam que não havia dúvidas e que estava tudo direitinho.

Também foi fácil adivinhar como modificar a eletrodinâmica, caso alguém quisesse modificá-la. Simplesmente mudei a $\delta$ para uma $f$, como faria no caso clássico. Era fácil, uma coisa simples. Para descrever a velha teoria retardada sem menção explícita de campos e tinha que escrever probabilidades, não só amplitudes. Teria que elevar ao quadrado minhas amplitudes e isso envolveria integrais de caminho duplas nas quais haveria dois $S$ 's e assim por diante. Mas, enquanto eu avançava com todas essas coisas e estudava formas diferentes e condições de contorno diferentes, fiquei com a sensação engraçada de que as coisas não estavam exatamente como deveriam. Não podia identificar claramente a dificuldade e, durante um dos curtos períodos durante os quais eu imaginei que havia deixado tudo em paz, publiquei uma tese e recebi meu doutorado.

Durante a guerra, não tive tempo de trabalhar nessas coisas com muito empenho, mas ficava pensando dentro do ônibus e tal, com pequenos pedaços de papel, e lutava para avançar e acabei descobrindo de fato que havia algo errado, algo terrivelmente errado. Descobri que se generalizasse a ação partindo da bela Lagrangiana (3) para a forma (1), então as quantidades que havia definido como energia, etc. seriam complexas. As energias dos estados estacionários não seriam reais e as probabilidades dos eventos não somariam 100\%. Ou seja, se você considerasse as probabilidades de isto acontecesse e de que aquilo acontecesse - de tudo que pudesse acontecer - elas não somariam um.

Outro problema com o qual lutei duramente era como representar elétrons relativísticos com essa nova mecânica quântica. Eu queria um jeito único e diferente não apenas copiar os operadores de Dirac em alguma expressão e usando algum tipo de álgebra de Dirac em vez de números complexos comuns. Fui muito encorajado pelo fato de que em uma dimensão espacial encontrei uma maneira de associar uma amplitude a cada caminho me limitando a caminhos que iam apenas para frente e para trás na velocidade da luz. A amplitude era simplesmente $(i \epsilon)$ elevado a uma potência igual ao número de inversões na velocidade, onde divido o tempo em passos $\epsilon$ e permito que a velocidade seja revertida apenas nesses momentos. Isso dá (quando $\epsilon$ vai a zero) a equação de Dirac em duas dimensões - uma dimensão espacial e uma temporal $(\hbar=m=e=1)$.

A função de onda de Dirac tem quatro componentes em quatro dimensões, mas nesse caso ela tem apenas duas componentes e essa regra para a amplitude de um caminho automaticamente produz a necessidade de duas 
componentes. Porque se essa é a fórmula para a amplitude de um caminho, saber a amplitude de todos os caminhos que chegam a um dado ponto não vai adiantar para obter a amplitude de chegar ao próximo ponto. Isso acontece porque para o próximo instante, se ela veio da direita, não há novo fator $(i \epsilon)$ se ela for para a direita, ao passo que se ela veio da esquerda há um novo fator $(i \epsilon)$. Assim, para levar adiante a informação para o próximo momento, não é suficiente saber a amplitude total de chegada, mas temos de saber a amplitude de chegar pela direita e a amplitude de chegar pela esquerda, separadamente. Se soubermos isso, podemos calcular as duas de novo e temos que carregar as duas amplitudes para formar uma equação diferencial (de primeira ordem no tempo).

Eu sonhava que, se fosse esperto, acharia uma fórmula para a amplitude de um caminho que fosse bela e simples em três dimensões espaciais e uma temporal, que seria equivalente à equação de Dirac e da qual as quatro componentes matriciais e todas as outras propriedades matemáticas estranhas decorreriam como simples consequências - nunca tive sucesso com isso. Mas eu quis mencionar algumas das coisas que não deram em nada e nas quais despendi quase tanto esforço quanto nas que funcionaram.

Para resumir a situação nos anos logo após a guerra, eu diria que eu tinha muita experiência com eletrodinâmica, pelo menos sabia muitas maneiras diferentes de formulá-la em termos de integrais de caminho envolvendo ações e de outras maneiras. Um dos subprodutos importantes, por exemplo, de ter muita experiência com essas formas simples foi que era fácil ver como combinar o que era chamado naqueles dias de campos longitudinais e transversais e, em geral, de ver claramente a invariância relativística da teoria. Devido à necessidade de fazer as coisas de forma diferencial tinha havido, na eletrodinâmica quântica tradicional, uma completa divisão do campo em duas partes, uma chamada de longitudinal e a outra mediada por fótons ou ondas transversais. A parte longitudinal era descrita por um potencial de Coulomb agindo instantaneamente na equação de Schrödinger, enquanto a parte transversal tinha uma descrição inteiramente diferente, em termos da quantização das ondas transversais. Essa separação dependia da inclinação relativística dos eixos no espaço-tempo. Observadores se movendo a velocidades diferentes iriam separar o mesmo campo em campos longitudinais e transversais de maneiras diferentes. Além disso, toda a formulação da mecânica quântica, que insistia na função de onda em cada instante, era difícil de analisar relativisticamente. Outra pessoa em um sistema de coordenadas diferentes calcularia a sucessão de eventos em termos de funções de ondas em seções diferentes do espaço-tempo e com uma separação diferente entre partes longitudinal e transversal. A teoria Hamiltoniana não parecia ser relativisticamente invariante - apesar de ser, é claro. Uma das grandes vantagens do ponto de vista mais geral era que dava pra ver a invariância relativística diretamente ou, como diria Schrödinger, a covariância era manifesta. Eu tinha a vantagem, portanto, de ter uma forma manifestamente covariante para a eletrodinâmica quântica, com sugestões para modificações e coisa e tal. Eu tinha a desvantagem de que se eu a levasse realmente a sério - e mesmo se a levasse só um pouco a sério - eu tinha problemas com essas energias complexas e o fiasco com as probabilidades e assim por diante. Eu estava lutando sem sucesso com isso.

Então Lamb fez seu experimento, medindo a separação do níveis ${ }^{2} S_{\frac{1}{2}}$ e ${ }^{2} P_{\frac{1}{2}}$ do hidrogênio, encontrando cerca de 1000 megaciclos de diferença nas frequências. O Professor Bethe, com quem eu estava associado em Cornell, é um homem que tem esta característica: se há um bom número experimental, é preciso encontrá-lo a partir da teoria. Assim, ele forçou a eletrodinâmica da época a dar uma resposta para a separação entre esses níveis. Ele observou que a auto-energia do elétron é infinita e, portanto, a energia de um elétron ligado também deveria ser infinita. Mas, quando calculássemos a separação dos dois níveis de energia em termos da massa corrigida em vez da massa original, ele pensava, a teoria daria respostas finitas. Ele fez uma estimativa da separação dessa maneira e encontrou que ainda era divergente, mas suspeitou que isso se devia ao fato de ter usado uma teoria não-relativística da matéria. Supondo que seria convergente no tratamento relativístico, ele estimou que obteria cerca de mil megaciclos para o Lamb-shift e, portanto, fez a mais importante descoberta da história da teoria da eletrodinâmica quântica. Ele descobriu isso no trem vindo de Ithaca, Nova York, para Schenectady e me ligou todo excitado de Schenectady para me contar o resultado, que eu não me lembro de ter compreendido completamente na época.

Voltando a Cornell, ele deu um seminário sobre o tema, ao qual eu compareci. Ele explicou que é complicado entender qual termo infinito corresponde a quê quando tentamos fazer correções para a mudança infinita na massa. Se houvesse quaisquer modificações, ele disse, ainda que fisicamente incorretas (ou seja, não necessariamente da maneira que a natureza funciona) mas quaisquer modificações que fossem a altas frequências, que tornassem essas correções finitas, então não haveria problema em descobrir como manter tudo sob controle. Basta calcular a correção finita $\Delta m$ para a massa do elétron $m$, substituir o valor numérico de $m+\Delta m$ em lugar de $m$ nos resultados para qualquer outra situação e todas as ambiguidades seriam resolvidas. Se, além disso, esse método fosse relativisticamente invariante, então teríamos absoluta certeza de como fazê-lo sem destruir a invariância relativística.

Depois do seminário, fui até ele e disse "posso fazer isso, vou trazer amanhã". Eu acho que sabia todas as maneiras de modificar a eletrodinâmica conhecidas pelo homem, na época. Então, cheguei no dia seguinte e expliquei o que corresponderia à modificação da função $\delta$ para $f$ e 
pedi a ele para explicar como calcular a auto-energia do elétron, por exemplo, para vermos se era finita.

Quero que percebam um ponto importante. Não levei em conta o conselho do Professor Jehle para tentar encontrar uma aplicação. Nunca usei aquele maquinário que tinha construído para resolver um único problema relativístico. Eu não tinha nem calculado a auto-energia do elétron até então; estava estudando as dificuldades com a conservação da probabilidade e tal, sem fazer nada concreto exceto discutir as propriedades gerais da teoria.

Mas agora eu estava falando com o Professor Bethe, que me explicou na lousa, conforme trabalhamos juntos, como calcular a auto-energia do elétron. Até aquele momento as integrais eram logaritmicamente divergentes. Contei a ele como fazer modificações relativisticamente invariantes que achei que deixariam tudo certo. Montamos a integral e ela divergia com a sexta potência da frequência em vez de logaritmicamente!

Voltei ao meu quarto e pensei naquilo e fiquei andando em círculos, tentando entender o que estava errado. Eu estava seguro de que fisicamente tudo tinha que ser finito, não podia entender por que estava dando infinito. Fiquei mais e mais interessado e finalmente percebi que tinha de aprender como fazer o cálculo. Então, estudei como calcular a auto-energia do elétron trabalhando pacientemente no meio da terrível confusão daqueles dias, com estados de energia negativa e buracos e contribuições longitudinais e tudo mais. Quando finalmente entendi como fazer e fiz as modificações que tinha sugerido, tudo funcionou e deu finito, como eu esperava. O Professor Bethe e eu nunca descobrimos o que tínhamos feito errado na lousa dois meses antes, mas parece que apenas erramos em algum lugar e nunca conseguimos descobrir onde. $\mathrm{O}$ que eu tinha proposto, se tivéssemos feito a conta sem errar, teria dado certo e teria dado uma correção finita. De qualquer maneira, me forçou a olhar tudo de novo e a me convencer fisicamente que nada poderia dar errado. Seja como for, a correção da massa agora era finita e proporcional a $\log (a)$ onde $a$ é a largura da função $f$ que substituímos em lugar de $\delta$. Quem quiser uma eletrodinâmica não modificada, tem de tomar $a$ tendendo a zero e vai obter uma correção de massa infinita. Mas isso não importa. Mantendo a finito, segui o programa delineado pelo Professor Bethe e mostrei como calcular um monte de coisas, o espalhamento de elétrons por átomos sem radiação, os deslocamentos de níveis e assim por diante, calculando tudo em termos da massa experimental e notando que os resultados, como sugerido por Bethe, não eram sensíveis a $a$ e até tinham um limite finito quando $a \rightarrow 0$.

O resto do meu trabalho era simplesmente melhorar as técnicas então disponíveis para cálculos, criando diagramas que ajudavam a analisar mais rapidamente a teoria de perturbação. A maior parte dos resultados era primeiramente adivinhado - eu não tinha uma teoria relativística da matéria. Por exemplo, parecia-me óbvio que as velocidades nas fórmulas não-relativísticas teriam de ser substituídas por matrizes $\alpha$ de Dirac ou, nas fórmulas mais relativísticas, pelos operadores $\gamma_{\mu}$. Eu tirava meus palpites das formas com as quais tinha trabalhado usando integrais de caminho para matéria não-relativística, mas luz relativística. Era fácil criar regras de substituição para o caso relativístico. Fiquei muito surpreso ao descobrir que não era sabido que as fórmulas que haviam sido desenvolvidas tão pacientemente através da separação em ondas longitudinais e transversais poderiam ser obtidas apenas da fórmula das ondas transversais se, em vez de somar sobre apenas as duas direções perpendiculares de polarização, somássemos sobre todas as quatro direções de polarização. Que isso sempre funcionaria era tão óbvio olhando para a ação (1) que eu achei que fosse de conhecimento geral. Eu tinha discussões com as pessoas porque não percebia que elas não sabiam disso. Mas todo o trabalho cuidadoso delas com as ondas longitudinais era sempre equivalente a simplesmente estender a soma sobre duas direções transversais de polarização para todas as quatro direções. Essa era uma das vantagens curiosas do método. Ademais, eu incluí diagramas para os vários termos da série perturbativa, melhorando a notação, descobrindo formas fáceis de fazer as integrais que apareciam nesses problemas, etc. e fiz uma espécie de manual sobre como fazer eletrodinâmica quântica.

Mas um passo importante que era fisicamente novo envolvia a energia negativa do mar de Dirac, que me causou tanta dificuldade lógica. Fiquei tão confuso que me lembrei da velha ideia de Wheeler de que talvez o pósitron fosse um elétron andando de volta no tempo. Assim, na teoria de perturbação dependente do tempo que era usada para calcular a auto-energia, eu imaginei que poderíamos ir para trás no tempo e verificar quais termos obtínhamos por meio de reversão temporal. Eram os mesmos termos que outras pessoas obtinham quando tratavam o problema de maneira mais complicada, usando buracos no mar [de Dirac], com exceção, talvez, dos sinais. Esses eu determinava empiricamente ao inventar e testar algumas regras.

Tentei explicar como todas a melhorias da teoria relativística foram, de início, malandragens semi-empíricas mais ou menos diretas. A cada vez que eu descobria alguma coisa nova eu voltava e checava muitas vezes, comparava com todos os problemas já resolvidos em eletrodinâmica (e, mais tarde, em teoria de mésons fracamente acoplados) para ver se iria concordar sempre, até que ficasse absolutamente convencido da verdade das várias regras e ajustes que havia inventado para simplificar o trabalho.

Durante esse tempo, outros haviam desenvolvido a teoria dos mésons, um assunto que eu não tinha estudado em detalhes. Fiquei interessado na possível aplicação dos meus métodos a cálculos perturbativos em teoria de mésons. Mas, o que era teoria de mésons? Tudo que eu sabia era que a teoria de mésons era meio análoga à eletrodinâmica, exceto que as partículas que correspondiam ao fóton tinham massa. Era fácil adivinhar que a função 
$\delta$ em (1), que era solução de d'Alembertiano igual a zero, teria de ser substituída pela solução correspondente de d'Alembertiano igual a $\mathrm{m}^{2}$. Depois, havia tipos diferentes de mésons: os mais próximos do fóton, acoplados via $\gamma_{\mu} \gamma_{\mu}$, eram chamados de mésons vetoriais e havia também mésons escalares. Bem, talvez isso correspondesse a colocar um no lugar de $\gamma_{\mu}$, talvez fosse o que eles chamavam de "acoplamento pseudo vetorial" e eu poderia tentar adivinhar o que aquilo devia ser. Eu não tinha conhecimento para entender a maneira com que eram definidos nos artigos convencionais porque tudo era expressado na época em termos de operadores de criação e aniquilação, que eu não tinha aprendido direito. Eu me lembro que quando alguém começou a me ensinar a respeito de operadores de criação e aniquilação, que este operador cria um elétron, eu disse "como você cria um elétron? Isso viola a conservação de carga" e foi assim que bloqueei minha mente para o aprendizado de um esquema muito prático de cálculo. Portanto, eu tinha que buscar todas as oportunidades possíveis de testar se tinha adivinhado corretamente o conteúdo das várias teorias.

Um dia surgiu uma discussão no encontro da Sociedade de Física sobre um cálculo do Professor Slotnik relacionado à interação de um elétron e um neutron, usando teoria pseudo escalar e com acoplamento pseudo vetorial e também com teoria pseudo escalar e com acoplamento pseudo escalar. Ele tinha encontrado que essas respostas não eram iguais. De fato, de acordo com uma teoria os resultados eram divergentes, mas eram convergentes na outra. Algumas pessoas acreditavam que as duas teorias deviam dar os mesmos resultados para o problema. Era uma boa oportunidade de testar minhas adivinhações e ver se eu realmente entendia o que esses acoplamentos eram. Então, eu fui para casa e, durante a noite, resolvi o espalhamento elétron-nêutron para os acoplamentos pseudo escalar e pseudo vetorial, vi que não eram iguais e os subtraí e calculei a diferença em detalhes. No dia seguinte, no encontro, vi Slotnik e disse "Slotnik, resolvi o problema ontem à noite e gostaria de ver se obtive as mesmas respostas que você. Eu obtive uma resposta diferente para cada acoplamento, mas quero checar os detalhes com você porque quero ter certeza dos meus métodos". E ele disse "como assim, você resolveu a noite passada, eu levei seis meses!". Quando comparamos as respostas ele olhou para mim e disse "o que é este $Q$ aqui, esta variável $Q$ ?" (eu tinha expressões tipo $\left(\tan ^{-1} Q\right) / Q$ etc.) Eu disse, "é o momento transferido pelo elétron, defletido em diferentes ângulos". "Ah, não", ele disse, "eu só tenho o valor limite quando $Q$ tende a zero; o espalhamento frontal". Bem, era fácil substituir $Q$ por zero nas minhas fórmulas e, nesse caso, eu obtive as mesmas respostas que ele tinha. Mas ele tinha levado seis meses só para fazer o caso sem transferência de momento, enquanto em apenas uma noite eu tinha tratado o caso com transferência de momento finita e arbitrária. Foi um momento emocionante para mim, como receber o Prêmio
Nobel, porque me convenceu que, finalmente, eu tinha um tipo de método e de técnica e entendia como fazer coisas que outras pessoas não sabiam como fazer. Foi um momento de triunfo no qual percebi que realmente tinha tido sucesso em obter algo de valor.

Nessa época fui estimulado a publicar, porque todo mundo dizia que parecia ser um meio fácil de fazer contas e queriam saber como usar. Tive que publicar faltando duas coisas; uma era provar todas as afirmações, no sentido matemático convencional. Muitas vezes, do ponto de vista de um físico, eu não tinha uma demonstração de como obter todas as regras e equações da eletrodinâmica convencional. Mas eu sabia por experiência, por tentativa e erro, que tudo era de fato equivalente à eletrodinâmica regular e eu tinha provas parciais de várias partes, embora nunca tivesse realmente sentado, como Euclides fez para o geômetras da Grécia, e garantido que era possível obter tudo a partir de um conjunto simples de axiomas. Como resultado, o trabalho foi criticado, não sei se de forma favorável ou desfavorável, e o "método" foi chamado de "método intuitivo". Para aqueles que não percebem, entretanto, eu gostaria de enfatizar que há um monte de trabalho envolvido em usar de modo satisfatório esse "método intuitivo". Pelo fato de que nenhuma prova clara e simples das fórmulas está disponível, é necessário realizar uma quantidade anormal de checagens e rechecagens de consistência e veracidade em termos do que é sabido, comparando com exemplos análogos, casos limite, etc. Na ausência de demonstração matemática direta, é preciso ser cuidadoso para ter certeza do resultado e empenhar um esforço perpétuo de demonstrar as fórmulas tanto quanto possível. Ainda assim, muito mais coisas certas podem ser sabidas do que provadas.

Precisa ficar claro que em todo esse trabalho eu estava representando a eletrodinâmica convencional com interação retardada, e não a minha teoria meio-avançada e meio-retardada que corresponde a (1). Eu só usei (1) para adivinhar as fórmulas. Uma das fórmulas que eu adivinhei correspondia a mudar a $\delta$ para uma função $f$ de largura $a^{2}$, para que pudesse calcular resultados finitos para todos os problemas. Isso me traz à segunda coisa que ficou faltando quando publiquei o artigo, uma dificuldade não resolvida. Com $\delta$ trocada por $f$, a conta dava resultados que não eram "unitários", ou seja, para is quais a soma das probabilidades de todas as alternativas não era um. O desvio da unidade era bem pequeno, na prática, se $a$ fosse pequeno. No limite em que eu tomava $a$ bem pequeno, não fazia diferença. Então, o processo de renormalização podia ser realizado, podíamos calcular tudo em termos da massa experimental e depois tomar o limite e a dificuldade aparente de que a unitariedade era temporariamente violada desaparecia. Eu não era capaz de demonstrar que isso sempre aconteceria.

Por sorte, eu não esperei a solução desse problema porque, até onde sei, ninguém teve sucesso ainda em resolver essa questão. Minha experiência com teorias de mésons com acoplamentos mais fortes e com mésons vetoriais 
fortemente acoplados, ainda que não prove nada, sugere que, se o acoplamento fosse mais forte, ou se fôssemos até uma ordem bem alta (ordem 137 em teoria de perturbação para eletrodinâmica), essa dificuldade permaneceria e teríamos problemas. Ou seja, acredito que não há uma eletrodinâmica quântica realmente satisfatória, mas não tenho certeza. E acredito que uma das razões para o lento progresso atual no entendimento de interações fortes é que não há nenhum modelo teórico relativístico para o qual se possa realmente calcular tudo. Ainda que seja sempre dito que a dificuldade está no fato das interações fortes serem difíceis de calcular, eu acho que é porque as interações fortes em teoria de campo não têm solução, não fazem sentido - elas ou são infinitas ou, se tentarmos modificá-las, a modificação destrói unitariedade. Eu não acho que temos um modelo quântico relativístico completamente satisfatório, nem mesmo um que não concorde com a natureza mas que pelo menos concorde com a lógica de que a soma das probabilidades de todas as alternativas tem de ser $100 \%$. Portanto, eu acho que a teoria de renormalização é simplesmente uma maneira de varrer as dificuldades com divergências da eletrodinâmica para baixo do tapete. Não tenho, naturalmente, certeza disso.

Assim termina a história do desenvolvimento de uma visão espaço-temporal da eletrodinâmica quântica. Perguntome se algo pode ser aprendido com essa história. Duvido. O mais marcante é que a maioria das ideias desenvolvidas durante essa pesquisa acabaram não sendo usadas no resultado final. Por exemplo, o potencial metade avançado e metade retardado não foi usado, a expressão (1) da ação não foi usada, a ideia de que cargas não agem sobre elas mesmas foi abandonada. A formulação de integrais de caminho da mecânica quântica foi útil para adivinhar as expressões finais e para formular a teoria geral da eletrodinâmica de novas maneiras - ainda que não fosse estritamente necessária. O mesmo vale para a ideia do pósitron como elétron voltando ao passado, era conveniente mas não estritamente necessária para a teoria, porque é exatamente equivalente ao ponto de vista do mar de energia negativa.

É impressionante o grande número de pontos de vista diferentes e formulações matemáticas muito diferentes que são equivalentes umas às outras. O método usado aqui, de pensar em termos físicos, parece extremamente ineficiente. Olhando para trás, só posso sentir remorso pela quantidade enorme de raciocínio físico e elaboração matemática que terminam meramente reexpressando o que já era sabido, ainda que em uma forma muito mais eficiente para o cálculo de problemas específicos. Não teria sido mais simples trabalhar inteiramente dentro do contexto matemático para elaborar uma expressão mais eficiente? Isso realmente pareceria ser o caso, mas precisamos notar que apesar de o problema resolvido ter sido apenas uma reformulação, o problema original era o (possivelmente ainda não resolvido) problema de evitar os infinitos da teoria usual. Assim, uma nova teoria foi bus- cada, não apenas uma reformulação da anterior. Mesmo que a busca tenha sido infrutífera, é preciso olhar para a questão do valor das ideias físicas no desenvolvimento de uma nova teoria.

Muitas ideias diferentes podem descrever a mesma realidade física. Assim, eletrodinâmica clássica pode ser descrita por meio de campos, ou por uma ação à distância, etc. Originalmente, Maxwell encheu o espaço com engrenagens e Faraday com linhas de campo, mas as equações de Maxwell em si mesmas são pristinas e independentes da elaboração em palavras que tenta uma descrição física. A única descrição física verdadeira é aquela que descreve o significado experimental das quantidades da equação - ou melhor, a maneira pela qual as equações devem ser usadas para descrever observações experimentais. Se for assim, talvez a melhor maneira de proceder seja tentar adivinhar equações e deixar de lado modelos físicos ou descrições. Por exemplo, McCullough adivinhou as equações corretas para propagação de luz em um cristal muito antes que seus colegas, que usavam modelos elásticos, pudessem começar a entender o fenômeno, ou ainda, Dirac obteve sua equação para descrição do elétron através de proposições quase que puramente matemáticas. Uma visão física simples pela qual todo o conteúdo dessa equação pode ser visto parece ainda estar faltando.

Portanto, acho que adivinhar equações pode ser o melhor método para avançar na obtenção de leis para a parte da física que ainda não é entendida. Por outro lado, quando eu era mais jovem eu tentei adivinhar equações, e já vi muitos estudantes tentando fazê-lo, e é fácil ir em direções totalmente erradas e impossíveis. Acho que o problema não é encontrar o melhor ou mais eficiente método que leva a uma descoberta, mas encontrar qualquer método que seja. Raciocínio físico ajuda algumas pessoas a fazer sugestões sobre como o desconhecido pode estar relacionado ao conhecido. Teorias sobre o conhecido, que são descritas por ideias físicas diferentes podem ser equivalentes em suas predições e portanto cientificamente indistinguíveis. Entretanto, não são psicologicamente idênticas quando tentamos sair dessa base em direção ao desconhecido. Isso porque visões diferentes sugerem tipos diferentes de modificações que podem ser feitas e portanto não são equivalentes em relação às hipóteses que podemos gerar a partir delas em nossa tentativa de entender o que ainda não foi entendido. Eu acho que um bom físico teórico hoje em dia acharia útil ter uma ampla gama de pontos de vista físicos e expressões matemáticas para a mesma teoria (por exemplo, eletrodinâmica quântica) disponíveis. Talvez isso seja pedir demais de uma pessoa. Mas os novos estudantes, como classe, deveriam ter isso. Se cada estudante individual segue a mesma moda atual ao expressar e pensar sobre eletrodinâmica ou teoria de campo, então a variedade de hipóteses sendo geradas para entender as interações fortes, digamos, é limitada. Talvez corretamente, pois é possível que a chance seja grande de que a verdade esteja 
mesmo na direção da moda. Mas, na eventualidade de que esteja em outra direção - uma direção que é óbvia para uma visão alternativa da teoria de campo - quem vai encontrá-la? Somente alguém que tenha se sacrificado para aprender sozinho eletrodinâmica quântica a partir de um ponto de vista peculiar e incomum, um que ele teve que inventar por si mesmo. Digo sacrificado porque essa pessoa provavelmente não vai ganhar nada com isso, porque a verdade pode estar em outra direção, talvez aquela da moda.

Mas, se minha experiência serve de guia, o sacrifício não é muito grande porque se o ponto de vista peculiar for realmente equivalente ao usual do ponto de vista experimental no campo do que é conhecido, há sempre uma gama de aplicações e problemas nesse campo para os quais o ponto de vista especial dá um poder e uma clareza de pensamento especiais, o que tem valor em si mesmo. Ademais, na busca por novas leis, temos sempre a excitação psicológica de sentir de talvez ninguém mais tenha pensado naquela possibilidade maluca que estamos considerando em algum momento.

Então, o que aconteceu com a velha teoria pela qual eu me apaixonei na juventude? Bem, eu diria que se tornou uma velha senhora, na qual restaram hoje poucos atrativos, e que os corações dos jovens não irão mais palpitar ao olhar para ela. Mas podemos dizer dela que foi uma mãe muito boa e criou excelentes filhos. Agradeço a Academia Sueca de Ciências por premiar um deles. Obrigado.

\section{Referências}

[1] R.P. Feynman, Phys. Rev. 76, 749 (1949).

[2] R.P. Feynman, Phys. Rev. 76, 769 (1949).

[3] V. Pleitez, Richard Feynman e a QED, nesta edição especial da RBEF. 